\title{
Pad Dosage Form
}

National Cancer Institute

\section{Source}

National Cancer Institute. Pad Dosage Form. NCI Thesaurus. Code C69016.

A solid composed of a soft, non-adhesive and absorbent piece of fabric or other material. 